\title{
- Designing Adaptive Roles for Socially Assistive Robots: A New Method to Reduce Technological Determinism and Role Stereotypes
}

\author{
Andreas Huber, Lara Lammer, Astrid Weiss, and Markus Vincze \\ ACIN Institute of Automation and Control \\ Vienna University of Technology, Vienna, Austria
}

\begin{abstract}
Social roles are a design option for robots that behave in accordance with user expectations. We believe that robots have to exceed stereotypical role behaviors and dynamically provide roles that suit the people's living conditions in order to achieve long-term acceptance. We are introducing a new user-focused design method to develop social role repertoires for adaptive human-robot interaction (HRI). The method consists of five sequential steps: (1) user group and application scenario identification; (2) acquisition of users' mental associations; (3) derivation of role traits; (4) prioritization of these traits; and (5) synthesis of an adaptive social role repertoire. We tested our method with two specific user groups: elder adults living at home and those living in care facilities. The results reveal basic role concepts and specific preference clusters in each user group. The empirically based clusters are suitable for the parameterizations and development of robots with adaptive social roles.
\end{abstract}

Keywords: social roles, socially assistive robots, human-robot interaction, acceptance, elderly

\section{Introduction}

Contemporary research in social robotics considers the implementation of behavior based on social roles to be crucial to successful long-term human-robot interaction (HRI). As Mahani and Eklundh (2009) stated, "If through long-term use these [service robots] gain social skills, they could be supportive of some social roles that people might assign to them" (p. 4). The social roles for designing robot behavior are adapted from existing professions and social positions, such as those of butlers, nurses, and nannies. Dautenhahn et al. (2005) conducted one of the first investigations into the social roles that a robot companion might have in their COGNIRON project. When asked, "What role should a future robot companion in the home have?" the majority of people wanted the robot to be an assistant. The second most popularly chosen role was machine/appliance, and the third, servant. Only a few people could imagine the robot companion as a "friend" or "mate." Study participants confirmed stereotypical traditional work roles for a robot to be suitable, such as those of household assistant, gardener, and security guard. All of these roles originate from the human domain. The scientists concluded that the desire of people to have a robot as a servant could be fulfilled by a robot butler. They remarked that in order to be achieved in a satisfying manner (including robotic etiquette), effectively achieving this role would require great awareness and sensitivity on the part of the robot.

\footnotetext{
All authors had a significant role in preparing the paper and share responsibility for its content. Authors retain copyright and grant the Journal of Human-Robot Interaction right of first publication with the work simultaneously licensed under a Creative Commons Attribution License that allows others to share the work with an acknowledgement of the work's authorship and initial publication in this journal.
}

Journal of Human-Robot Interaction, Vol. 3, No. 2, 2014, Pages 100-115, DOI 10.5898/JHRI.3.2.Huber 
Due to the challenges of implementing pre-defined stereotypical roles derived from the human domain, robot roles are often reduced to assumed core functionalities, or, in the words of Mahani and Eklundh (2009), "the task roles of the robot." According to Mahani and Eklundh, the task role of a robot needs to be defined prior to its social role. A study by Forlizzi (2007) showed that even if a robot vacuum cleaner had no previously assigned social role in the household, people tended to ascribe social values to it. The social role emerged from the enacted task role. In this approach suggested by Mahani and Eklundh, the robot role is based on the stereotypical functionality (pre-defined by the technical constraints and imagination of the behavior designers). The role lacks the ability to adapt to the user's living conditions in the long run. In our opinion, however, robotic products have to overcome stereotypical functionality and fulfill not only one social role, but rather role repertoires. In doing so, the robot's behavior will most likely fit its owner's changing preferences and needs.

To derive potential social roles for robots, considerable research has been done from a usercentered perspective. These studies mainly use interviews and questionnaires completed by potential end users (Beer et al., 2012; Dautenhahn et al., 2005; Lohse, Hegel, \& Wrede, 2008; Mahani \& Eklundh, 2009). We argue that these user-centered approaches only offer a starting point for establishing an understanding of potential roles and applications that a robot could take on in a household. They do not tap into the full potential of sociology's social role concept. We offer an alternative user-focused approach for designing social roles and identifying specific roletrait clusters for socially assistive robots to help in designing behavior patterns that support user acceptance of the robot's social role over time.

The application of our user-focused method is a five-step procedure: (1) identification of the user target group and the basic application scenario, (2) a picture-based association study with a small sample of participants, (3) derivation of core behavior traits from the association study, (4) a questionnaire-based study with a bigger sample to validate these core behaviors and to take into account the impact of socio-demographic variables, and (5) synthesis of adaptive social roles by combining core behaviors with the demographic data. The central methodological component of our approach is to avoid the term "robot" and any other robot-related stimuli (videos, pictures, potential scenarios, etc.) in order to reduce technological determinism-presuming that the technology should determine the social roles.

The novelty of our work is twofold: First, we want to offer a new methodology based on sociological theory for defining social role repertoires. Second, we are not focusing on a traditional user-centered approach that couples questionnaires and interviews in order to understand user needs. We intentionally chose a robot-stimulus-free approach that does not focus on the robot's task role, but rather on its social role.

To verify our method, we conducted a multi-centered study in Austria with a target group of elderly participants (aged 70 and up). We identified social roles for a domestic care robot that would enable longer independent living at home. The results are a collection of social role repertoires describing the preferences and needs of this user group. The social role repertoire can be adapted to specific user needs and preferences for domestic care robots.

The article is structured as follows: First, we will describe the topic of social roles from a sociological perspective, as this is the foundation of our work, followed by a short overview of how social roles have been considered so far in the HRI research community. Next, we will describe how to apply our method in order to derive social role repertoires using two empirical studies. We then describe the social role repertoires derived for users aged 70 and over for a domestic care robot that would enable longer independent living at home, followed by a description of how this role repository could be integrated into HRI behavior. We close the paper with a sociological reflection on our approach and recommendations for fellow researchers on how to apply our approach to other HRI domains. 


\section{Social Roles}

Socially assistive robots and how interactions with them could be designed has been extensively studied using various social roles, such as "robot companion." Such role descriptions usually make use of traditional work professions or animal roles, such as butlers, servants, and pet-like helpers (Dautenhahn et al., 2005; Fong, Nourbakhsh, \& Dautenhahn, 2003). Often the roles are arbitrary, arising from the robot's desired functionality or form. We suggest a more theoretical and generalizable approach to the concept of social role. To make the concept concrete, we provide an example of a servant role suitable for socially assistive robots. This role is considered in the context of a household scenario and will serve to link role concepts with a practical example.

\subsection{Sociological Perspective}

Originally developed by sociologists (Dahrendorf, 2006; Schimank, 2007), social roles describe "a set of standards, descriptions, norms, or concepts held for the behaviors of a person or social position; or (less often) a position itself" (Biddle, 1979, p. 9). In sociology, there are different categories of social roles:

1) Cultural roles affect everyday life as "self-evident." They are often only recognizable and tangible during strong social changes, such as during the transformation of political systems, foundation of religions, or political and social conflicts. For instance, the cultural roles characterized as "female" or "male" were challenged, differentiated, and modified in Western industrialized societies by the feminist movement.

2) Differentiated social roles describe various professional roles, such as teacher and shop assistant, that emerged as a result of the division of labor since industrialization.

3) Situation-specific roles are formed spontaneously and ad hoc, for example, when an inebriated person appears at a funeral. In such particular social settings, and during norm violations, people improvise their roles and behavior within their biopsychosocial framework (e.g., scapegoating).

4) Biosociological roles are closely related to the animalist nature of man. Primates and humans apparently recognize "dominant" or "loud" individuals, who assume dominating or aggressive roles. In groups, people develop special forms of behavior to these individuals (Claessens, 1968).

Roles are occupied by individuals in a social system. They can be considered as "agents" of the system, characterized by a capacity to act independently and to make choices (Barker, 2005). An agent can play a social role by fulfilling the expectations associated with his or her social position in society or culture (Dahrendorf, 2006; Schimank, 2007). Social roles are gradually developed through the repetition of social interaction patterns that support the stability of social organizations. The set of all of an agent's performable roles is called his role repertoire.

An agent can handle roles dynamically in six specific ways, known as role mechanisms (Herrmann, Jahnke, \& Loser 2004; Jahnke, Ritterskamp, \& Herrmann, 2005; Long \& Murphy, 2006). These mechanisms define a role's life cycle within a dynamic social context:

1) Role assignment is the process of assigning a role to an agent in a social system. It is a statement of desire, not a guarantee that the actor will accept or be able to play the role. The servant role is assigned by the members of the household, and joining the household is an implicit acceptance of this role assignment.

2) Role taking occurs when an agent uses the known role played by another agent to create a mental model of the other agent's behavior. This process requires a shared role understanding. Role taking is often erroneously confused with role assignment (Coutu, 1951). Taking a social role requires a shared understanding of associated expectations and position. If one servant encounters another coming out of a room, the first servant's model of the other creates the expectation that the departed area has been cleaned.

3) Role change. An agent may play one or more roles simultaneously or in sequence. Role change is the process of relinquishing a role and assuming another (e.g., in an emergency 
situation). A servant might switch to another role, such as that of a paramedic upon encountering an injured victim.

4) Role making characterizes how agents play a role in their own unique manner, and how they transform expectations into concrete actions. Role making depends on the agent's knowledge, personality, and capabilities, and the expectations and environment created by the social system. A servant might have specific knowledge about the preferences and needs of his employer. This servant would play a role in a different manner than a servant without this information.

5) Inter-role conflict. An agent may hold multiple roles, but the goals of each role may conflict. This conflict results from the differing demands of various roles. A servant might note serious health problems of his employer. The servant offers to help but is rejected. This information would conflict with the role's core support function and must be resolved.

6) Role definition. Existing roles are dynamic. Therefore, the definition of a role may change over time due to changing circumstances. Change may include the function as well as the expectations of the reference group: New tasks may be added, some tasks may be modified, and new behaviors may be expected. Role definition is the most important mechanism for long-term adaptation within a dynamic social context. Introduction of new technologies, such as social media, influence how the servant role is performed and change how the agent interacts with others in the household.

\subsection{Social Robotics Perspective}

The well-established paradigm of social roles gained entry into the field of socially assistive robotics through computer science and the interdisciplinary area of HRI. Feil-Seifer and Mataric (2005) have argued that socially assistive robots have the goal of providing assistance to human users and that this should happen through social interaction. This definition takes into account the above-mentioned sociological concept of social roles. However, in robotics, this paradigm is used "primarily as a synonym for task, without many of the stronger social aspects; these uses of roles appear to be strictly limited to role-assignment and role-change" (Long \& Murphy, 2006, p. 5). Accordingly, the original role concept from sociology is a reduced tool used mainly for assigning and allocating tasks. The other role mechanisms have not been feasible due to contemporary computational shortcomings (Colman \& Han, 2005).

The last role mechanism, role definition, can be considered the key to long-term adaptation and has the highest computational requirements. These requirements include the autonomous recognition of shortcomings in the robot's current role and the generation of appropriate behavioral alterations. At present, the design of robot behaviors suffers from this lack of role definition mechanisms.

A question we have to ask ourselves as HRI researchers is, "Why do we come up with social roles for robots?" When building social robots, we have to find a balance between the expectations people have toward a robot and the capabilities of the machine. Stereotypical roles can be considered one solution for shaping expectations and thereby easing interaction and user acceptance (Lohse et al., 2008).

In the community, there is an increasing interest in designing social robot behavior. In a first step, different levels of sociality were defined regarding what social robots could be. An example is Breazeal's levels (2003): socially evocative, socially interfaced, socially receptive, and sociable. Fong et al. (2003) proposed other levels: socially situated, socially embedded, and socially intelligent robots. However, these levels only cover capabilities a robot must have in order to fit in, but do not take into account its task role or the application scenario. Christensen (2003 postulated three potential commercial application categories for domestic robots: entertainment, everyday tasks, and assistance to older and handicapped adults. A more detailed categorization of application scenarios for domestic robots was described by Sung and colleagues. Using a generative design approach, they identified three domestic tasks people desire for robotic assistance: taking over time-consuming chores, house-sitting, and personal attendance (Sung et al., 2009). 
There are several studies investigating how robots need to be designed to play a role in people's everyday lives. These studies mainly focus on specific application areas and scenarios as well as task roles and their related expectations from a user-centered perspective. Lohse and her colleagues tried to identify with an online survey which application scenarios people could imagine for domestic robots. Participants responded to the appearance and functionality of four social robots (AIBO, iCat, BIRON, and BARTHOC). The authors demonstrated that, depending on the robot's appearance, participants considered robots suitable for domestic roles or a public context (Lohse et al., 2008). Similarly focusing on task roles, Lee and colleagues developed a robot that delivers snacks. To achieve long-term HRI, these authors stress the necessity of iterative design processes including studies of the robot's services (e.g., delivering snacks), prototyping, empirical user testing, and form factor design studies (Lee et al., 2009).

Researchers with a psychological perspective have tried to address individual needs and normative expectations. Kahn's (1998) questionnaire study assessed people's attitude toward getting help from a domestic robot, offering one of the first recommendations for robot developers aimed to address user needs and expectations in terms of appearance design and functionality. Similarly, Oestreicher, Hüttenrauch, and Severinsson-Eklund (1999) conducted a questionnaire study to identify preferred physical and behavioral factors of a robot's actions, such as speed, complexity, and diversity. The user's individual interests have been the focus of later usercentered design approaches reported in the research literature. For example, Ljungblad (2006) and Jacobsson, Ljungblad, Bodin, Knurek, \& Holmquist (2007) interviewed owners of exotic pets to investigate the characters that people like. They used the concept of personas to guide their design process and to develop personalities for artificial agents. Meerbeek, Saerbeck, Bartneck (2009) illustrated a feasible method for developing 'personas' for robotic products; this method can be used to develop design guidelines.

Norms are known to affect social roles. Nass and Moon (2002) carried out a series of experimental studies showing that people unconsciously attribute social rules and gender stereotypes to computers. Later research demonstrated that robots are expected to follow the social norms of humans in many situations (Sardar, Joosse, Weiss, \& Evers, 2012). Norms are also included in some guidelines that Bartneck and Forlizzi (2004) compiled for the design of social robots: First, the form of a social robot should match the expectations of the user; second, it should be able to communicate verbally and nonverbally with the user; and third, it should be able to take human social norms into consideration.

All of the aforementioned studies use application scenarios and task roles as the main basis for empirical work. In many cases, questionnaires and interviews are used after participants interact with a robot, watch a movie about a robot, or hear definitions of what a robot could be or do in the future. We argue that these methods potentially block our view of the broader social roles domestic robots that could play in future. Thus, in this article, we present a methodological approach to show how role repertoires for HRI can be derived. Starting from the social role (not the task role) and not involving a robot at the beginning, our approach reduces stereotyped technological bias.

Additionally, our approach considers the methodological limitations of the persona concept, namely that personas are fictional and have no clear relationship to real users (Chapman \& Milham, 2006). The steps in our method are iteratively reviewed by the target group to ensure theoretical and empirical traceability of results.

The following section describes how we applied the method in a case study conducted with elderly users aged 70 or more years old. The purpose was to identify the dynamic social role of a domestic care robot that should enable them to stay home longer.

\section{Application of the Method}

To demonstrate and test our design method, we conducted a study following the five-step procedure summarized above. First, we defined a target group and the basic domain of the robot. 
Then, we conducted a small qualitative study $(\mathrm{N}=18)$ to gather associations concerning role descriptions for functionality (Körtner et al., 2012) without mentioning a robot. From these associations, we derived concrete trait items that we used in a questionnaire for a larger quantitative study $(\mathrm{N}=182)$. The results were analyzed along with demographic data to identify social roles repertoires. Both studies were conducted by experts in the fields of social robotics, nursing science, and psychology.

\subsection{The Target Group}

As our method is intended to identify role repertoires for socially assistive robots, we consider older users potentially in need of a care robot that enables them to remain living independently at home. Older adults and people with disabilities have already been envisioned as two of the main target groups for assistive robots (Feil-Seifer \& Mataric, 2005).

For the qualitative study and the later quantitative study, we recruited participants from Haus der Barmherzigkeit, an Austrian multi-centered care facility specializing in the field of geriatrics and long-term care of patients with chronic diseases. We also invited some persons living at home to participate. Inclusion criteria for both studies included men and women, aged 70 or more years old. The participants had to be able to read, write, and communicate without limitations. They were able to participate whether or not they depended on external help. We included participants living at home independently as well as in residential assisted-living situations. We did not expect to find differences depending on the participant's living situation. We did not offer incentives during the recruitment process. Participants living in care facilities were surveyed within their daily environment.

The interviews for qualitative study were conducted following the basics of qualitative research (Corbin \& Strauss, 2007). The qualitative study took place on two different dates in March 2012.

The quantitative study was performed from May to August 2012. The scope of the questionnaire was taxing for the majority of the participants living in care facilities. In those instances, we used face-to-face questionnaire administration instead of the planned paper-andpencil approach. The questionnaire included items to assess the participants' demographic background: gender, year of birth, housing situation (at home or in a care facility), and living environment (urban or rural). All participants and their caregivers were informed about data protection regulations and the scientific use of the study's information.

\subsection{Qualitative Association Study Procedure}

For our first step, the qualitative association study, we thought it especially important to provide clearly defined instructions. All participants needed to have exactly the same notion of the "helper" that they were supposed to describe. This notion was therefore described to not trigger ideas about robots, in order to prevent technologically colored associations. Every participant in the qualitative association study and the quantitative questionnaire study was given the following definition of a "helper":

Imagine a helper who lives by your side with you at your home. This helper supports you in many ways as well as in emergency situations. This helper can be anyone or anything and look as you want in your fantasy.

We never used the priming word "robot" to prevent participants from immediately thinking of robot stereotypes. Furthermore, to avoid suggesting a particular role, we decided to use the basic term "helper" instead of other common alternatives from social robotics, such as "companion," "butler," and "housekeeper."

The participants were asked to choose three to seven pictures out of thirty-one photographs from the following six pre-set categories: animals (e.g., dog, cat), people (e.g., nurse, butler), nature (e.g., tree, flower), furniture (e.g., lamp, chest of drawers), technical devices (e.g., television, telephone) and fantasy-creatures (e.g., genie, clown). We asked, "Which of the ollowing pictures suit your definition of a helper best and why?" During the picture associations, 
participants were asked about the connotations linked to the picture and why they chose that particular picture. We adapted this method from traditional clinical psychology (e.g., Rorschach, TAT) (Murray, 1943), in which pictures are used to detect individuals' connotations and associations as well as unconscious motives, feelings, and fantasies. By using picture associations instead of direct questions, we aimed to gain richer answers by exposing unconscious concepts of a helper.

Table 1. "The helper of my dreams..." - List of derived helper behaviors from the qualitative association study used to create items for the questionnaire study. Numbers indicate the order of the item in the questionnaire.

\begin{tabular}{|c|l|c|l|c|l|}
\hline $\mathbf{1}$ & $\begin{array}{l}\text { pays attention to } \\
\text { cleanness, tidiness and } \\
\text { my furniture. }\end{array}$ & $\mathbf{8}$ & $\begin{array}{l}\text { is partner-like and } \\
\text { shares my habits. }\end{array}$ & $\mathbf{1 5}$ & $\begin{array}{l}\text { helps me to be } \\
\text { mindful of my health. }\end{array}$ \\
\hline $\mathbf{2}$ & $\begin{array}{l}\text { is communicative and } \\
\text { likes to chat. }\end{array}$ & $\mathbf{9}$ & $\begin{array}{l}\text { motivates me to do } \\
\text { physical exercise } \\
\text { and activity. }\end{array}$ & $\mathbf{1 6}$ & $\begin{array}{l}\text { is always ready to } \\
\text { fulfil my requests. }\end{array}$ \\
\hline $\mathbf{3}$ & $\begin{array}{l}\text { helps me to stay in } \\
\text { contact with relatives } \\
\text { and friends. }\end{array}$ & $\mathbf{1 0}$ & $\begin{array}{l}\text { is caring, warm- } \\
\text { hearted and appears } \\
\text { calming. }\end{array}$ & $\mathbf{1 7}$ & $\begin{array}{l}\text { is leisurely and never } \\
\text { in a hurry. }\end{array}$ \\
\hline $\mathbf{4}$ & $\begin{array}{l}\text { is calm, not } \\
\text { conspicuous and stays } \\
\text { in the background. }\end{array}$ & $\mathbf{1 1}$ & $\begin{array}{l}\text { asks me for help if } \\
\text { he/she can't handle } \\
\text { something. }\end{array}$ & $\mathbf{1 8}$ & $\begin{array}{l}\text { is frugal and } \\
\text { autonomous. }\end{array}$ \\
\hline $\mathbf{5}$ & $\begin{array}{l}\text { is cheerful and radiates } \\
\text { joy. }\end{array}$ & $\mathbf{1 2}$ & $\begin{array}{l}\text { helps organize my } \\
\text { daily routine. }\end{array}$ & $\mathbf{1 9}$ & $\begin{array}{l}\text { is sympathetic and } \\
\text { listens to me. }\end{array}$ \\
\hline $\mathbf{6}$ & $\begin{array}{l}\text { could teach me } \\
\text { something new. }\end{array}$ & $\mathbf{1 3}$ & $\begin{array}{l}\text { provides access to } \\
\text { news and internet. }\end{array}$ & $\mathbf{2 0}$ & $\begin{array}{l}\text { offers music, } \\
\text { entertainment and } \\
\text { reading material. }\end{array}$ \\
\hline $\mathbf{7}$ & $\begin{array}{l}\text { is cuddly and enjoys } \\
\text { snuggling. }\end{array}$ & $\mathbf{1 4}$ & $\begin{array}{l}\text { is glad if I teach } \\
\text { him/her something } \\
\text { new. }\end{array}$ & $\mathbf{2 1}$ & is always close to me. \\
\hline
\end{tabular}

Following the phenomenological methodology in qualitative research (Moustakas, 1994), we derived twenty-one concepts from ninety picture associations gathered during the qualitative study. In the first step, participants' written picture associations were transferred to an Excel file. The authors read the participants' descriptions carefully until coming to a substantial understanding, overview, and "sense" of the material. The aim was to distinguish relevant, not physical, helper traits. We read the descriptions three times in no particular order. We did not have an aim of testing validity or any specific hypothesis. In a second step of analysis, we synthesized the ninety transformed associations into categories. This categorization was focused on descriptions concerning "what" trait the helper should have and "how" the helper should act. The categories derived varied in content depending upon the associations from which they originated. We developed categories iteratively and repeated consultations of raw data continued in a hermeneutic manner.

\subsection{Quantitative Questionnaire Study Procedure}

From the qualitative study, twenty-one different categories emerged reflecting possible role behaviors (see Table 1). These categories were then adapted to create questionnaire items in the subsequent study. The questionnaire consisted of three parts. In the first part, an introduction about data protection, the aim of the study, and the affiliation of the researchers were given to the participants. The second part consisted of one multiple-choice question in which the participants could choose their personal preferred traits of a helper. The participants were asked to choose 
three behaviors, which for them best suits a helper. To ensure consistency, every participant was given the same the definition of a "helper" as previously described in the qualitative association study. The third section contained a series of questions to assess participants' demographic characteristics. The results of the quantitative study were analyzed with regard to chosen "helper" traits and demographic background.

Table 2. Demographic characteristics of the participants in each study $(\mathrm{SD}=$ standard deviation).

\begin{tabular}{|c|c|c|c|c|}
\hline & \multicolumn{2}{|c|}{ Qualitative } & \multicolumn{2}{|c|}{ Quantitative } \\
\hline & $\begin{array}{l}\text { Home } \\
(\mathrm{N}=10)\end{array}$ & $\begin{array}{c}\text { Care Facility } \\
(\mathbf{N}=8)\end{array}$ & $\begin{array}{c}\text { Home } \\
(\mathrm{N}=\mathbf{8 5})\end{array}$ & $\begin{array}{c}\text { Care Facility } \\
(\mathbf{N}=95)\end{array}$ \\
\hline $\begin{array}{l}\text { Age (years) } \\
\text { Mean (SD) }\end{array}$ & $60.40(8.11)$ & $83.00(8.82)$ & $69.52(8.77)$ & $82.71(10.33)$ \\
\hline $\begin{array}{l}\text { Gender } \\
\text { Male (n [\%]) } \\
\text { Female (n [\%]) } \\
\text { Unknown (n [\%]) }\end{array}$ & $\begin{array}{l}4(40.0 \%) \\
6(60.0 \%) \\
0(0.0 \%)\end{array}$ & $\begin{array}{l}3(37.5 \%) \\
5(62.5 \%) \\
0(0.0 \%)\end{array}$ & $\begin{array}{c}38(44.7 \%) \\
47(55.3 \%) \\
0(0.0 \%)\end{array}$ & $\begin{array}{c}24(25.26 \%) \\
70(73.69 \%) \\
1(1.05 \%)\end{array}$ \\
\hline $\begin{array}{l}\text { Living Environment } \\
\text { Urban (n [\%]) } \\
\text { Rural (n [\%]) } \\
\text { Unknown (n [\%]) }\end{array}$ & $\begin{array}{l}\mathrm{n} / \mathrm{s} \\
\mathrm{n} / \mathrm{s} \\
\mathrm{n} / \mathrm{s}\end{array}$ & $\begin{array}{l}\mathrm{n} / \mathrm{s} \\
\mathrm{n} / \mathrm{s} \\
\mathrm{n} / \mathrm{s}\end{array}$ & $\begin{array}{c}57(67.06 \%) \\
26(30.59 \%) \\
2(2.35 \%)\end{array}$ & $\begin{array}{c}56(58.95 \%) \\
36(37.89 \%) \\
3(3.16 \%)\end{array}$ \\
\hline $\begin{array}{l}\text { Motion impairment } \\
\text { condition }\end{array}$ & $\begin{array}{c}\text { No } \\
\text { impairment }\end{array}$ & $\begin{array}{l}\text { Moderate, } \\
\text { severe }\end{array}$ & $\begin{array}{c}\text { No } \\
\text { impairment }\end{array}$ & $\begin{array}{l}\text { Moderate, } \\
\text { severe }\end{array}$ \\
\hline
\end{tabular}

\section{Findings on Role Repertoires}

Two participants from the "living at home" group did not fill in the second section (helper traits) of the questionnaire, thus demographic data for these participants was not included in the analysis. The demographic background of participants was almost the same in the qualitative and the quantitative studies (see Table 2). The fact that there were more women in care facilities than living at home can be explained by their higher life expectancy (Kalben, 2002). Overall, the average age was higher for participants in residential assisted-living situations.

The most frequently chosen helper traits of both groups were trait one, "tidiness," and fifteen, "health care" (Figure 1). Using a two-tailed Mann-Whithey U-test, we found seven significant differences in preferred helper traits between those living at home versus those living in the care facility (Figure 1, Table 3). None of the preferred helper traits were associated with the rural or urban living environment of the participants in either group. 
Huber et al.. Designing Adaptive Roles for Socially Assistive Robots

Table 3a. Traits that were significantly more often mentioned by persons living at home.

\begin{tabular}{|c|l|c|c|c|c|c|}
\hline Trait & \multicolumn{1}{|c|}{$\begin{array}{c}\text { Brief } \\
\text { description }\end{array}$} & $\begin{array}{c}\mathbf{n} \\
(\mathbf{n o m e})\end{array}$ & $\begin{array}{c}\mathbf{n} \\
(\mathbf{c a r e} \\
\text { facility })\end{array}$ & $\mathbf{U}$ & $\boldsymbol{p}$ & Significance \\
\hline 9 & $\begin{array}{l}\text { Organizes phys. } \\
\text { exercises }\end{array}$ & $\begin{array}{c}28 \\
(32.94 \%)\end{array}$ & $\begin{array}{c}12 \\
(12.63 \%)\end{array}$ & 4857.5 & 0.001111 & $* *$ \\
\hline 18 & $\begin{array}{l}\text { Frugal \& } \\
\text { autonomous }\end{array}$ & $\begin{array}{c}14 \\
(16.47 \%)\end{array}$ & $\begin{array}{c}3 \\
(3.18 \%)\end{array}$ & 4575 & 0.002384 & $* *$ \\
\hline 12 & $\begin{array}{l}\text { Organizes daily } \\
\text { routine }\end{array}$ & $\begin{array}{c}30 \\
(35.29 \%)\end{array}$ & $\begin{array}{c}20 \\
(21.05 \%)\end{array}$ & 4612.5 & 0.03385 & $*$ \\
\hline
\end{tabular}

Table $3 \mathrm{~b}$. Traits that were significantly more often mentioned by persons living in care facilities.

\begin{tabular}{|c|l|c|c|c|c|c|}
\hline Trait & \multicolumn{1}{|c|}{$\begin{array}{c}\text { Brief } \\
\text { description }\end{array}$} & $\begin{array}{c}\mathbf{n} \\
(\text { home })\end{array}$ & $\begin{array}{c}\mathbf{n} \\
(\mathbf{c a r e} \\
\text { facility) }\end{array}$ & \multicolumn{1}{|c|}{$\mathbf{U}$} & $\boldsymbol{p}$ & Significance \\
\hline 21 & Presence & $\begin{array}{c}4 \\
(4.71 \%)\end{array}$ & $\begin{array}{c}22 \\
(23.16 \%)\end{array}$ & 3292.5 & 0.0004592 & $* * *$ \\
\hline 2 & Cheerfulness & $\begin{array}{c}18 \\
(21.18 \%)\end{array}$ & $\begin{array}{c}35 \\
(36.84 \%)\end{array}$ & 3435 & 0.006751 & $* *$ \\
\hline 5 & Talkativeness & $\begin{array}{c}7 \\
(8.24 \%)\end{array}$ & $\begin{array}{c}22 \\
(23.16 \%)\end{array}$ & 3405 & 0.0218 & $*$ \\
\hline 19 & Listening & $\begin{array}{c}11 \\
(12.94 \%)\end{array}$ & $\begin{array}{c}24 \\
(25.26 \%)\end{array}$ & 3540 & 0.03776 & $*$ \\
\hline
\end{tabular}

$* p<.05, * * p<.01, * * * p<.001$ 
Huber et al.. Designing Adaptive Roles for Socially Assistive Robots

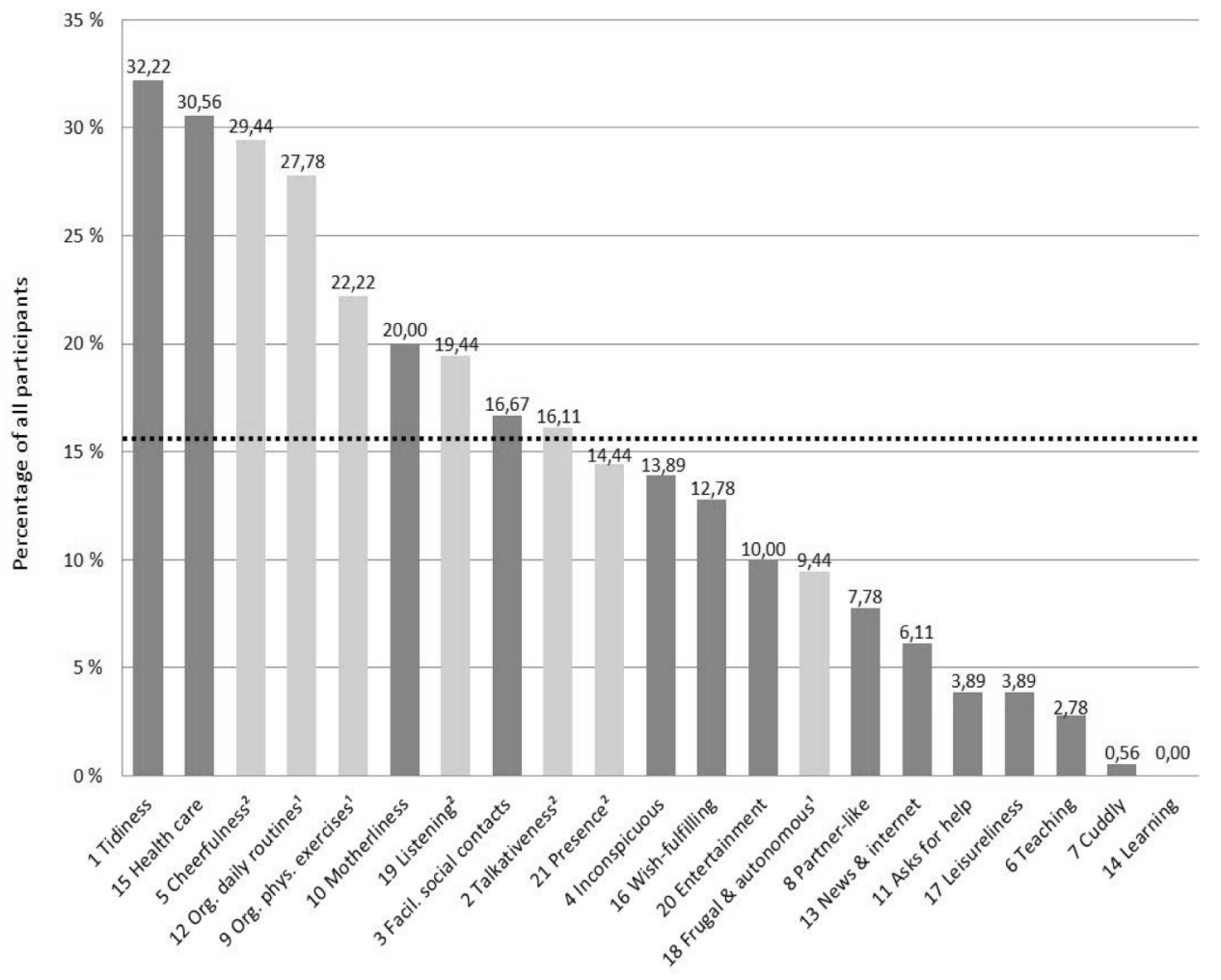

Figure 1. Frequency of chosen helper traits (both groups together).

${ }^{1}$ ) significantly more often mentioned by persons living at home.

$\left.{ }^{2}\right)$ significantly more often mentioned by persons living in care facilities.

The straight dotted line indicates the average frequency.

We performed a hierarchical cluster-analysis using the method of average linkage between groups and based on the Sørensen-Dice coefficient to identify specific clusters of helper traits (role repertoires) for each group. We used a maximal distance level according to the following considerations: (1) the resulting clusters must remain using the coefficients of Jaccard, Ochiai, Kulczynski I and Bray-Curtis as well as with the method of average linkage within groups, and (2) only traits with a high chance of being chosen together should be grouped indicating "natural" clusters. For the second point, we took only traits into account that were chosen by more than 10 percent of the participants.

The results of the hierarchical cluster-analysis presented in Figure $2 a$ and $2 b$ and in Table 4 reveal three clusters with multiple traits for each living situation. A cluster, in this sense, is defined as a conglomerate of two or more associated traits. Associations above a certain distance were considered to be weakly connected and were therefore of low interest. However, single traits with high selection frequencies can be summarized under "basic traits" of a helper, as illustrated in Table 4. These results can be used to define and develop concrete behavior repertoires for socially assistive robots, as the following section will show. 
Huber et al.. Designing Adaptive Roles for Socially Assistive Robots

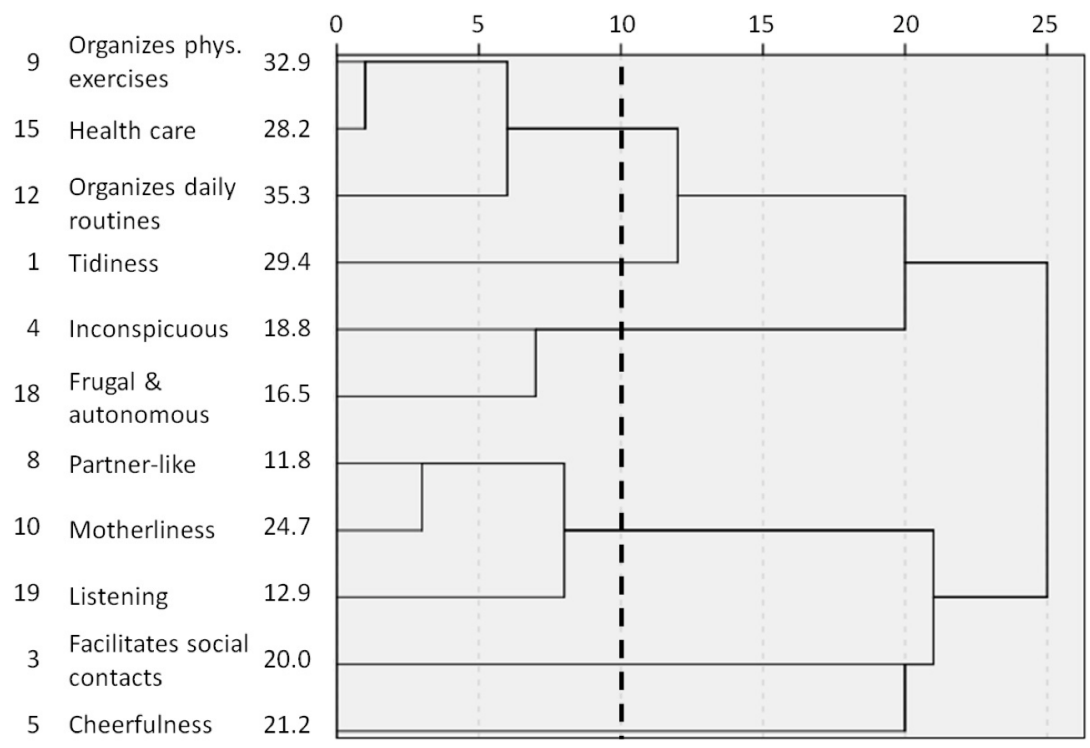

Figure 2a. Persons living at home can be grouped, according to their preferences, into three clusters: (9, 15 and 12), (4 and 18) and (8, 10 and 19).

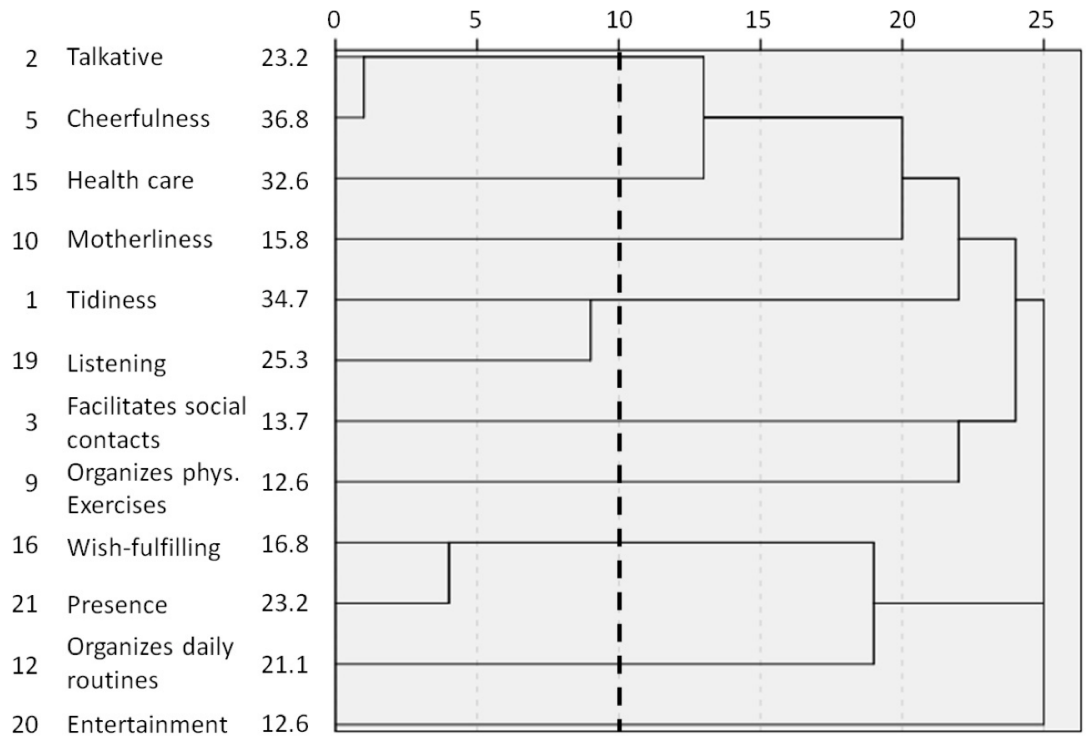

Figure $2 b$. Persons living in care facilities can be grouped, according to their preferences, into three clusters: (2 and 5), (1 and 19), and (16 and 21). Dendograms for both living situations were constructed using the average linkage-between-groups method based on the Sørensen-Dice coefficient. The numbers to the right of the traits indicate their selection frequency. Traits mentioned by less than 10 percent of the participants were not considered. 
Huber et al.. Designing Adaptive Roles for Socially Assistive Robots

\section{Defining Social Roles for People Aged 70 and Over}

The aim of this work was to demonstrate the value of our method by conducting two studies with users over 70 years of age who live at home or in residential assisted-living situations, asking them to tell us how they thought about a "helper." In both user groups, participants preferred positive personality traits and some specific role clusters.

Table 4. Differentiated role repertoire of a helper for users living at home and in care facilities. Each group prefers a different set of helper traits and several clusters of roles.

\begin{tabular}{|c|c|c|c|c|}
\hline $\begin{array}{l}\text { Basic } \\
\text { Role }\end{array}$ & $\begin{array}{l}\text { Living } \\
\text { Situation }\end{array}$ & Basic Traits & Adaptation Cluster & Adaptation Behaviors \\
\hline \multirow{6}{*}{ 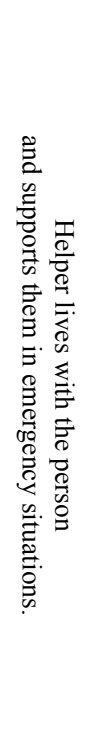 } & \multirow{3}{*}{ Home } & \multirow{3}{*}{$\begin{array}{l}\text { Tidiness, } \\
\text { Cheerfulness, } \\
\text { Facilitates social } \\
\text { contacts }\end{array}$} & $\begin{array}{l}\text { Home I: } \\
\text { Organizing Helper }\end{array}$ & $\begin{array}{l}\text { Organizes physical } \\
\text { exercises, Health care, } \\
\text { Organizes daily routines }\end{array}$ \\
\hline & & & $\begin{array}{l}\text { Home II: } \\
\text { Invisible Helper }\end{array}$ & $\begin{array}{l}\text { Inconspicuous, } \\
\text { Frugal \& autonomous }\end{array}$ \\
\hline & & & $\begin{array}{l}\text { Home III: } \\
\text { Empathic Helper }\end{array}$ & $\begin{array}{l}\text { Partner-like, } \\
\text { Motherliness, } \\
\text { Listening }\end{array}$ \\
\hline & \multirow{3}{*}{ Care Facility } & \multirow{3}{*}{$\begin{array}{l}\text { Health care, } \\
\text { Organizes daily } \\
\text { routines }\end{array}$} & $\begin{array}{l}\text { Care I: } \\
\text { Cheery Helper }\end{array}$ & $\begin{array}{l}\text { Talkativeness, } \\
\text { Cheerfulness }\end{array}$ \\
\hline & & & $\begin{array}{l}\text { Care II: } \\
\text { Regardful Helper }\end{array}$ & $\begin{array}{l}\text { Tidiness, } \\
\text { Listening }\end{array}$ \\
\hline & & & $\begin{array}{l}\text { Care III: } \\
\text { Serving Helper }\end{array}$ & $\begin{array}{l}\text { Wish-fulfilling, } \\
\text { Presence }\end{array}$ \\
\hline
\end{tabular}

As shown in Table 4, the elderly are a heterogeneous target group in terms of role expectations for helpers. Nonetheless, each group has basic and specific expectations. From the perspective of long-term HRI, an assistive robot can be provided with basic traits while also adapting to the individual needs of its owner over time. From these needs and preferences, one can derive concrete robot behaviors for the most interesting basic behaviors and role adaptation behaviors (for examples, see Table 5). Figure 3 illustrates the importance of the different role clusters for each living condition group. About three quarters of participants' preferences can be covered by the basic and specific role clusters. This figure also shows that -in addition to the "basic traits" - an adequately configured helper robot can further adapt its role to every second person using the "adaptation traits."

The basic traits are displayed by the robot from the start, whereas the specific adaptation behavior gradually appears in the following days and weeks. It is important to note that the user should have the option to evaluate and reject the newly emerging robot behaviors. From an ethical viewpoint, implementation of certain "social" preference clusters (e.g. cluster Home II or Care I) should be carefully considered and should not lead to the replacement of real social contacts. 
Huber et al.. Designing Adaptive Roles for Socially Assistive Robots
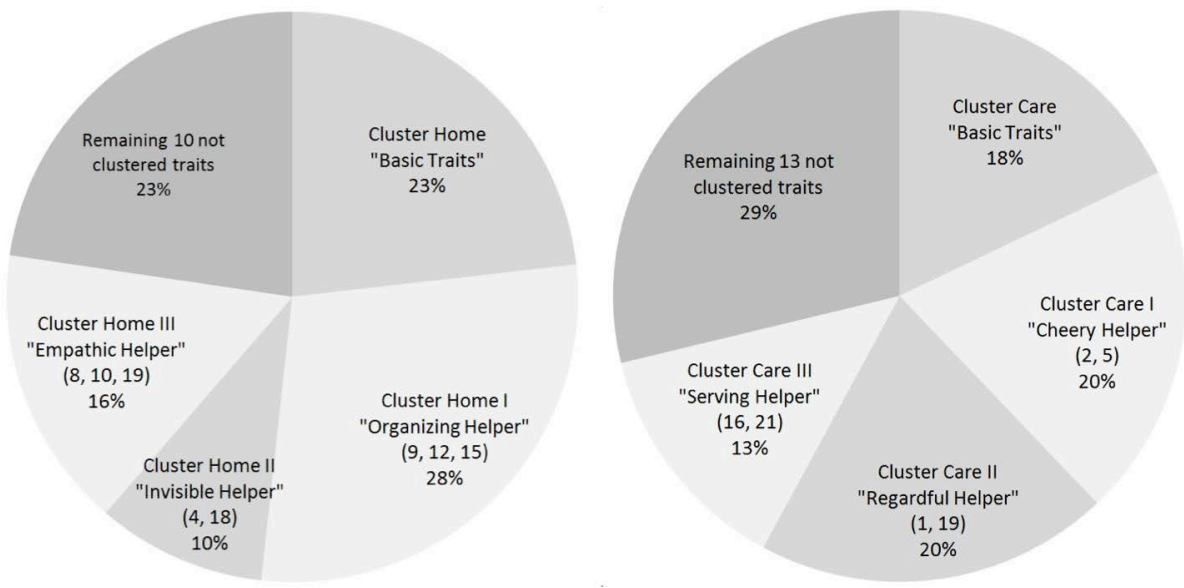

Figure 3. The importance of the clusters for each group: The percentages describe the probability that a person selects one or more traits of the respective cluster. The left (living at home) and the right (living in care facility) pie charts show that the identified clusters cover over 55 percent of participant response. The "basic traits" raise these values to 77 percent and 71 percent.

Table 5. Examples of how the cluster characteristics of Table 5 can be translated into concrete robot behaviors.

\begin{tabular}{|c|c|}
\hline Cluster Trait / Behavior & Implementation Example \\
\hline Cheerfulness & $\begin{array}{l}\text { The robot mentions positive events, such as the visit of a friend yesterday, the fine } \\
\text { weather today, etc. If the robot is alone, it whistles songs and giggles from time to } \\
\text { time. If asked, the robot plays the song or tells the joke that it was thinking about. }\end{array}$ \\
\hline $\begin{array}{l}\text { Facilitates social } \\
\text { Contacts }\end{array}$ & $\begin{array}{l}\text { The robot informs the user about the activities and preferences of friends and other } \\
\text { robot-users. It suggests to invite guests for joint activities, including watching } \\
\text { television, playing chess, cooking, dancing, etc. }\end{array}$ \\
\hline Frugal \& autonomous & $\begin{array}{l}\text { The robot has no own needs and preferences and only approaches the user in urgent } \\
\text { cases. }\end{array}$ \\
\hline Health care & $\begin{array}{l}\text { The robot provides delicious recipes using photos. It provides the possibility to } \\
\text { measure the user's blood pressure and easy-to-read statistics of the user's health } \\
\text { status. }\end{array}$ \\
\hline Inconspicuous & The robot performs its duties quietly and keeps distance from the user. \\
\hline Listening & $\begin{array}{l}\text { The robot always looks in the direction of the user and adapts its emotions } \\
\text { according to the conversational tone and content. }\end{array}$ \\
\hline Motherliness & $\begin{array}{l}\text { The robot regularly asks for the user's mental and physical condition while showing } \\
\text { caring/worrying emotions. It regularly gives positive reports concerning the safety } \\
\text { of the home, contents of the fridge, etc. }\end{array}$ \\
\hline Organizes daily routines & The robot provides schedules and reminders. \\
\hline $\begin{array}{l}\text { Organizes physical } \\
\text { exercises }\end{array}$ & $\begin{array}{l}\text { The robot provides instructions for physiotherapeutic exercises. It regularly asks to } \\
\text { dance with the user or asks if the user would like to go for a walk to take some new } \\
\text { photos for the robot's own album. }\end{array}$ \\
\hline Partner-like & $\begin{array}{l}\text { The robot adapts to the user's daily routines and has its own needs and preferences, } \\
\text { including decoration, physical contact, fun, etc. }\end{array}$ \\
\hline Presence & The robot tries to stay in the same room as the user. \\
\hline Talkativeness & $\begin{array}{l}\text { The robot proactively informs the user about the weather, reads newspaper } \\
\text { headlines, and wants to know more about other persons. }\end{array}$ \\
\hline Tidiness & $\begin{array}{l}\text { The robot proactively cleans the floor and keeps it free from clutter. It gives reports } \\
\text { about the home's cleanness, found objects, and objects on the floor that it cannot } \\
\text { move alone. }\end{array}$ \\
\hline Wish-fulfilling & $\begin{array}{l}\text { The robot has a functional and servile tone, showing only a few emotions and needs. } \\
\text { It times its recharging intervals in order to be continuously available, and the robot } \\
\text { can be summoned by using a call-button. }\end{array}$ \\
\hline
\end{tabular}


Huber et al.. Designing Adaptive Roles for Socially Assistive Robots

\section{Conclusion}

We introduce a new user-focused method to define social role repertoires for different living conditions based on sociological role theory. Our method consists of two main research steps: (1) an association test in order to identify primary traits and (2) a quantitative survey in order to define role repertoires. We demonstrated the application of this approach by using a case study of a socially assistive care robot that would enable longer independent living. We consider our approach a tool for system designers in deriving social roles and individual adaptation conditions for specific user groups. This tool reduces technological and stereotypical determinism. The intention of this method is to avoid prioritizing task application scenarios and robot functionalities as stimuli for identifying social roles of robots. Furthermore, it supports the design of specific robot roles that are not limited to technical constraints. The behavioral traits of the repertoire identified can later be implemented depending on technological opportunities. The empathic reflecting trait of a listening "helper" could, for example, be realized with unobtrusive dialogue and a robot head following the actions of the user.

Although not all-embracing, the derived list of helper traits turned out to be detailed enough for the design of a domestic care robot. However, we do not assume that we can extrapolate our findings to people in non-Western cultures or other demographic groups, unlike the groups we studied. We recommend that other potential user groups, such as young parents with young children, should be surveyed as to their socio-economic situation, values, wishes, and prospects. Additionally, we suggest considering an extended survey of demographic background characteristics, such as education, field of work/study, interest in technology, and pet ownership. Based on this information, the material for the first association study can be developed. We recommend involving experts from psychology, as the quality of the subsequent quantitative study will be dependent on the quality of the association material. Moreover, for data analysis of the quantitative study, we recommended using an exploratory approach in order to identify general and specific role-trait clusters beyond technological stereotypes.

In summary, the user-centered methodology introduced, together with clear results that lent support to this approach, is a promising option in the investigation of adaptive social roles for socially assistive robots.

\section{Acknowledgement}

We want to acknowledge the scientific staff of the Haus der Barmherzigkeit: Alexandra Schmid, Tobias Körtner, and Daliah Batko-Klein for their professional work concerning data gathering for our research study. Furthermore, we want to acknowledge Susanne Frennert from Lund University, Sara Kiesler from Carnegie Mellon University, and Annie Latham from FH Campus Wien, University of Applied Sciences for reviewing this paper.

\section{References}

Barker, C. (2005). Cultural studies: Theory and practice. London: Sage.

Bartneck, C., \& Forlizzi, J. (2004, September). A design-centered framework for social humanrobot interaction. In Proceedings of the 13th IEEE International Workshop on Robot and Human Interactive Communication, (ROMAN), 591-594. doi:10.1109/ROMAN.2004.1374827

Beer, J. M., Smarr, C., Chen, T. L., Prakash, A., Mitzner, T. L., Kemp, C. C., \& Rogers, W. A. (2012). The domesticated robot: Design guidelines for assisting older adults to age in place. In Proceedings of the 7th ACM/IEEE International Conference on Human-Robot Interaction (HRI), 335-342. Boston, MA. doi: 10.1145/2157689.2157806

Biddle, B. J. (1979). Role theory: expectations, identities, and behaviors. New York, NY: Academic Press. 
Huber et al.. Designing Adaptive Roles for Socially Assistive Robots

Breazeal, C. (2003). Toward sociable robots. Robotics and Autonomous Systems, 42(3), 167-175. doi: 10.1016/S0921-8890(02)00373-1

Christensen, H. I. (2003). Intelligent home appliances. In R. A. Jarvis and A. Zelinsky (Eds.), Robotics Research (pp. 319-327). Heidelberg, Germany: Springer Verlag.

Claessens, D. (1968). Rolle und Macht. (3rd ed.). Munich, Germany: Juventa.

Colman, A. W., \& Han, J. (2005). Organizational roles and players. In Proceedings of the AAAI

Fall Symposium on Roles, an Interdisciplinary Perspective: Ontologies, Programming Languages, and Multiagent Systems, 55-62. Arlington, VA.

Corbin, J., \& Strauss, A. (2007). Basics of qualitative research: Techniques and procedures for developing grounded theory (3rd ed.). Thousand Oaks, CA: Sage.

Coutu, W. (1951). Role-playing vs. role-taking: An appeal for clarification. American Sociological Review, 16(2), 180-187. doi: 10.2307/2087691

Dahrendorf R. (2006, 1958). Homo sociologicus. Ein Versuch zur Geschichte, Bedeutung und Kritik der Kategorie der sozialen Rolle. Wiesbaden, Germany: VS Verlag.

Dautenhahn, K., Woods, S., Kaouri, C., Walters, M. L., Koay, K. L., \& Werry, I. (2005). What is a robot companion-friend, assistant or butler? In Proceedings of the IEEE/RSJ International Conference on Intelligent Robots and Systems (IROS), 1192-1197. doi:

10.1109/IROS.2005.1545189.

Feil-Seifer, D., \& Mataric, M. J. (2005). Defining socially assistive robotics. In Proceedings of the 9th International Conference on Rehabilitation Robotics (ICORR), 465-468. Chicago, IL.

Fong, T., Nourbakhsh, I., \& Dautenhahn, K. (2003). A survey of socially interactive robots. Robotics and autonomous systems, 42(3), 143-166. doi: 10.1016/S0921-8890(02)00372-X

Forlizzi, J. (2007). How robotic products become social products: An ethnographic study of cleaning in the home. In Proceedings of the ACM/IEEE International Conference on HumanRobot Interaction, 129-136. Arlington, VA. doi: 10.1145/1228716.1228734

Herrmann, T., Jahnke, I., \& Loser, K.-U. (2004). The role concept as a basis for designing community systems. In F. Darses, R. Dieng, C. Simone, \& M. Zacklad (Eds.), Cooperative Systems Design, Scenario-Based Design of Collaborative Systems, (pp. 163-178). Amsterdam, the Netherlands: IOS Press.

Jacobsson, M., Ljungblad, S., Bodin, J., Knurek, J., \& Holmquist, L. E. (2007). GlowBots: Robots that evolve relationships. In Proceedings of the ACM Conference on Emerging Technologies (SIGGRAPH), 7. doi:10.1145/1278280.1278288.

Jahnke, I., Ritterskamp, C., Herrmann, T. (2005). Sociotechnical roles for sociotechnical systems-A perspective from social and computer sciences. In Proceedings of the AAAI Fall Symposium on Roles, an Interdisciplinary Perspective: Ontologies, Programming Languages, and Multiagent Systems. Arlington, VA.

Kalben, B. (2002). Mortality Differentials in Specified Age Groups. In Why men die younger: Causes of mortality differences by sex (17). Schaumburg, IL: Society of Actuaries

Khan, Z. (1998). Attitudes towards intelligent service robots. NADA, Royal Institute of Technology: Stockholm, Sweden.

Körtner, T., Schmid, A., Batko-Klein, B., Gisinger, C., Huber, A., Lammer, L., Vincze, M. (2012). How social robots make older users really feel well: A method to assess users' concepts of a social robotic assistant. In Proceedings of the 4th International Conference of Social Robotics (ICSR), 138-147. Chengdu, China. doi: 10.1007/978-3-642-34103-8_14

Lee, M. K., Forlizzi, J., Rybski, P. E., Crabbe, F., Chung, W., Finkle, J., Glaser, E., \& Kiesler, S. (2009). The Snackbot: Documenting the design of a robot for long-term human-robot interaction. 
Huber et al.. Designing Adaptive Roles for Socially Assistive Robots

In Proceedings of the 4th ACM/IEEE International Conference on Human Robot Interaction (HRI), 7-14. La Jolla, CA. doi: 10.1145/1514095.1514100

Ljungblad, S., Walter, K., Jacobsson, M., \& Holmquist, L. E. (2006). Designing personal embodied agents with personas. In Proceedings of the 15th IEEE International Symposium on Robot and Human Interactive Communication (ROMAN), 575-580. doi: 10.1109/ROMAN.2006.314451

Lohse, M., Hegel, F., \& Wrede, B. (2008). Domestic applications for social robots-An online survey on the influence of appearance and capabilities. Journal of Physical Agents, 2(2), 21-32.

Long M. T., \& Murphy R. R. (2006). The impact of autonomy and reasoning on social roles for robotics. Journal of Artificial Intelligence Research, 1, 1-10.

Mahani, M., \& Eklundh, K. S. (2009). A survey of the relation of the task assistance of a robot to its social role. Communication KCSa Royal Institute of Technology: Stockholm, Sweden.

Meerbeek, B., Saerbeck, M., \& Bartneck, C. (2009). Iterative design process for robots with personality. In Proceedings of the AISB Symposium on New Frontiers in Human-Robot Interaction. Edinburgh, Scotland.

Moustakas, C. (1994). Phenomenological research methods. Thousand Oaks, CA: Sage.

Murray, H. A. (1943). Thematic apperception test. Cambridge, MA: Harvard University Press.

Nass, C., \& Moon, Y. (2000). Machines and mindlessness: Social responses to computers. Journal of Social Issues, 56(1), 81-103. doi: 10.1111/0022-4537.00153

Oestreicher, L., Hüttenrauch, H., \& Severinsson-Eklund, K. (1999). Where are you going little robot? Prospects of Human-Robot Interaction. In Proceedings of the CHI 99 Basic Research Symposium, position paper. Pittsburgh, PA.

Sardar, A., Joosse, M., Weiss, A., \& Evers, V. (2012). Don't stand so close to me: Users' attitudinal and behavioral responses to personal space invasion by robots. In Proceedings of the Seventh Annual ACM/IEEE International Conference on Human-Robot Interaction, 229-230. doi: $10.1145 / 2157689.2157769$

Schimank, U. (2007): Handeln und Strukturen. Einführung in die akteurtheoretische Soziologie. In: K. Hurrelmann (Ed.), Grundlagentexte Soziologie (3rd ed.). Weinheim/München: Juventa Verlag.

Sung, J., Christensen, H. I., \& Grinter, R. E. (2009). Sketching the future: Assessing user needs for domestic robots. In Proceedings of the 18th IEEE International Symposium on Robot and Human Interactive Communication (RO-MAN), 153-158. doi: 10.1109/ROMAN.2009.5326289

Andreas Huber, Lara Lammer, Astrid Weiss, Markus Vincze; ACIN Institute of Automation and Control; Vienna University of Technology; Gusshausstr 27-29/E376; 1040 Vienna, Austria; Tel: +43-1-58801-37601; Email: huber.cognition@yahoo.com, lammer@acin.tuwien.ac.at, weiss@acin.tuwien.ac.at, vincze@acin.tuwien.ac.at 